\title{
Aerobic exercise did not have compensatory effects on physical activity levels in type 2 diabetes patients
}

Article in Journal of Sports Sciences · September 2014

DOI: 10.1080/02640414.2014.951875 · Source: PubMed

CITATIONS

0

5 authors, including:

\section{Bruno Moura}

Rio de Janeiro State University

17 PUBLICATIONS 22 CITATIONS

SEE PROFILE

\section{Janice Sepúlveda Reis}

Santa Casa de Belo Horizonte

36 PUBLICATIONS 250 CITATIONS

SEE PROFILE

\section{READS}

109

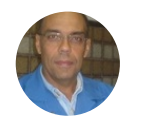

Joao Marins

Universidade Federal de Viçosa (UFV)

151 PUBLICATIONS 780 CITATIONS

SEE PROFILE

\section{Paulo Amorim}

Universidade Federal de Viçosa (UFV)

84 PUBLICATIONS 250 CITATIONS

SEE PROFILE

Some of the authors of this publication are also working on these related projects:

Análise da carga de esforço para melhoria do rendimento View project

Peripheral arterial disease complication levels, quality of life, balance, active and sedentary 
This article was downloaded by: [Bruno Moura]

On: 30 September 2014, At: 11:36

Publisher: Routledge

Informa Ltd Registered in England and Wales Registered Number: 1072954 Registered office: Mortimer House, 37-41 Mortimer Street, London W1T 3J H, UK

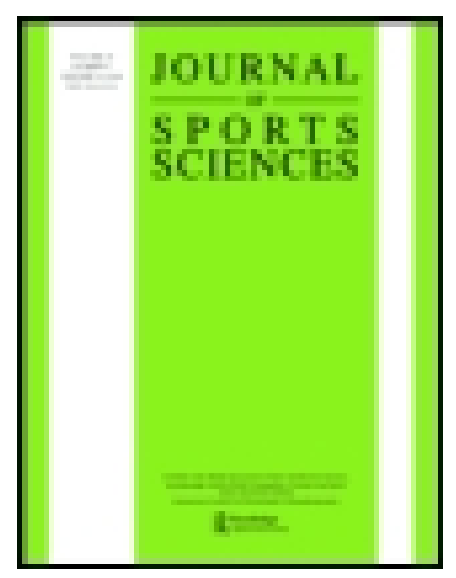

\title{
J ournal of Sports Sciences
}

Publication details, including instructions for authors and subscription information: http:// www.tandfonline.com/loi/ rjsp20

\section{Aerobic exercise did not have compensatory effects on physical activity levels in type 2 diabetes patients}

\author{
Bruno Pereira De Moura ${ }^{a}$, J oão Carlos Bouzas Marins ${ }^{a}$, Sylvia Do Carmo Castro Franceschini ${ }^{b}$, \\ J anice Sepúlveda Reis ${ }^{c} \&$ Paulo Roberto Dos Santos Amorim ${ }^{a}$ \\ ${ }^{a}$ Department of Physical Education, Human Performance Laboratory, Universidade Federal \\ de Viçosa, Viçosa, Brazil \\ ${ }^{\mathrm{b}}$ Department of Nutrition and Health, Universidade Federal de Viçosa, Viçosa, Brazil \\ ${ }^{c}$ Institute of Education and Research of Santa Casa de Belo Horizonte, IER-SCBH, Belo \\ Horizonte, Brazil \\ Published online: 26 Sep 2014.
}

To cite this article: Bruno Pereira De Moura, J oão Carlos Bouzas Marins, Sylvia Do Carmo Castro Franceschini, Janice Sepúlveda Reis \& Paulo Roberto Dos Santos Amorim (2014): Aerobic exercise did not have compensatory effects on physical activity levels in type 2 diabetes patients, J ournal of Sports Sciences, DOI: 10.1080/ 02640414.2014.951875

To link to this article: http:// dx. doi.org/ 10.1080/02640414.2014.951875

\section{PLEASE SCROLL DOWN FOR ARTICLE}

Taylor \& Francis makes every effort to ensure the accuracy of all the information (the "Content") contained in the publications on our platform. However, Taylor \& Francis, our agents, and our licensors make no representations or warranties whatsoever as to the accuracy, completeness, or suitability for any purpose of the Content. Any opinions and views expressed in this publication are the opinions and views of the authors, and are not the views of or endorsed by Taylor \& Francis. The accuracy of the Content should not be relied upon and should be independently verified with primary sources of information. Taylor and Francis shall not be liable for any losses, actions, claims, proceedings, demands, costs, expenses, damages, and other liabilities whatsoever or howsoever caused arising directly or indirectly in connection with, in relation to or arising out of the use of the Content.

This article may be used for research, teaching, and private study purposes. Any substantial or systematic reproduction, redistribution, reselling, loan, sub-licensing, systematic supply, or distribution in any form to anyone is expressly forbidden. Terms \& Conditions of access and use can be found at http:// www.tandfonline.com/page/terms-and-conditions 


\title{
Aerobic exercise did not have compensatory effects on physical activity levels in type 2 diabetes patients
}

\author{
BRUNO PEREIRA DE MOURA ${ }^{1}$, JOÃO CARLOS BOUZAS MARINS ${ }^{1}$, SYLVIA DO CARMO

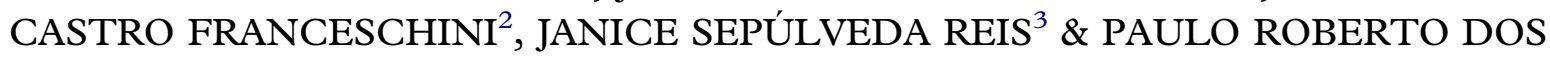 \\ SANTOS AMORIM ${ }^{1}$
}

${ }^{1}$ Department of Physical Education, Human Performance Laboratory, Universidade Federal de Viçosa, Viçosa, Brazil, ${ }^{2}$ Department of Nutrition and Health, Universidade Federal de Viçosa, Viçosa, Brazil and ${ }^{3}$ Institute of Education and Research of Santa Casa de Belo Horizonte, IER-SCBH, Belo Horizonte, Brazil

(Accepted 1 August 2014)

\begin{abstract}
Although exercise promotes beneficial effects in diabetic patients, some studies have questioned the degree of their importance in terms of the increase in total energy expenditure. In these studies, the decrease of physical activity levels (PAL) was referred as "compensatory effect of exercise". However, our aim was to investigate whether aerobic exercise has compensatory effects on PAL in type 2 diabetes patients. Eight volunteers $(51.1 \pm 8.2$ years) were enrolled in a supervised exercise programme for 8 weeks $\left(3 \mathrm{~d} \cdot \mathrm{wk}^{-1}, 50-60 \%\right.$ of $\mathrm{VO}_{2}$ peak for 30-60 min). PAL was measured using tri-axial accelerometers in the 1st, 8th and 12th weeks. Biochemical tests, cardiorespiratory fitness, anthropometric assessment and body composition were measured in the 2 nd and 11 th weeks. Statistical analysis was performed using non-parametric tests (Friedman and Wilcoxon, $P<0.05$ ). We found no significant differences in PAL between intervention periods, and participants spent the majority of their awake time in sedentary activities. However, the exercise programme generated a significant $14.8 \%$ increase in $\mathrm{VO}_{2}$ peak and a $15 \%$ reduction in fructosamine. The exercise programme had no compensatory effects on PAL in type 2 diabetes patients, but improved their cardiorespiratory fitness and glycaemic control.
\end{abstract}

Keywords: glycaemic control, daily activity, accelerometer, vector magnitude, ActiGraph

\section{Introduction}

Exercise (Colberg et al., 2010; Moura, Natali, Marins, \& Amorim, 2011) and physical activity (Meisinger, Lowel, Thorand, \& Doring, 2005) are important components of type 2 diabetes treatment with well-known benefits for the patients (Moura et al., 2014), in addition to being an important public health tool for the prevention and control of diabetes and its complications (Lindstrom et al., 2010; Paulweber et al., 2010; Yates et al., 2012).

However, although these terms are used synonymously by many health professionals, they have different definitions (Caspersen, Powell, \& Christenson, 1985). Physical activity is defined as body movement that is produced by the contraction of skeletal muscles and that increases energy expenditure above resting levels (e.g. daily activities, leisure time, occupational, housework and transport-related activity), while exercise refers to planned, structured and repetitive movement to improve or maintain one or more components of physical fitness. Exercise is a subcategory of physical activity (Caspersen et al., 1985).

Although exercise promotes beneficial effects in diabetic patients (Colberg et al., 2010; Moura et al., 2014), some studies (King et al., 2007; King, Hopkins, Caudwell, Stubbs, \& Blundell, 2008; Yates et al., 2014) have questioned the degree of their importance in terms of the increase in total energy expenditure. These studies report that for some people, the simple fact of enrolling in an exercise programme reduces their physical activity levels (PAL). This behaviour has been referred to as the compensatory effect (King et al., 2007) of exercise and acts in different ways - by promoting adjustments in energy expenditure in order to save energy, altering the appetite, stimulating increased food intake or even causing behavioural changes that reduce PAL, in other words, increasing the sedentary time (Levine, 2004).

However, no previous study has investigated the compensatory effects of exercise in type 2 diabetes 
patients. Thus, our aim was to investigate whether aerobic exercise has compensatory effects on PAL in type 2 diabetes patients.

\section{Methods}

\section{Participants}

Participant recruitment for this study occurred through advertisements in the local media, and respondents were selected according to the following inclusion criteria: (a) have type 2 diabetes diagnosed by ADA criteria (American Diabetes Association, 2014), (b) have no diabetes complications (cardiovascular disease, neuropathy, retinopathy and nephropathy), (c) must not have practised exercises with professional guidance in the 2 months preceding the start of the programme and (d) agreed not to do other kinds of exercise with professional guidance in addition to those in the programme during the study period and to maintain their usual diets throughout the intervention period.

Twenty volunteers signed up to participate in the study, 15 of whom satisfied the inclusion criteria. Following a meeting to explain the study procedures, 11 participants confirmed their participation. After the first week of the study, one was excluded due to an impediment in performing exercise because of ulceration on the feet. Two others gave up during the exercise programme for personal reasons. Eight participants (average age $51.1 \pm 8.2$ years, diagnosis: $5.1 \pm 4.6$ years ago), four of whom were women, formed the final sample. All participants had been on medication since the diagnosis of diabetes - metformin (Boulé et al., 2013), insulin and glimepiride. No participants reported changing his/her dose of medication during intervention. The sample was composed of the following professionals: Housemaid, Technical Administrative and University Professor.

All participants enrolled in this study had the approval of their physician to practise moderate intensity exercise and signed an informed consent. The study is in accordance with the provisions of the Declaration of Helsinki regarding research involving human participants and was approved by the Ethics Committee on Human Research of the Universidade Federal de Viçosa (Reference No.041/2010).

\section{Anthropometry and body composition assessment}

Anthropometric measurements were obtained at the Human Performance Laboratory, by a trained examiner. Weight, height and waist circumference measurements were performed using calibrated equipment based on the procedures described by Lohman and colleagues (Lohman, Roche, \& Martorell, 1988). Body mass index (BMI) was calculated and analysed according to the guidelines of the World Health Organization (WHO, 2003). Body composition was assessed using a Body Composition Analyser (BIA 310 bioimpedance analyzer, Biodynamics Corp.) (Lukaski, Bolonchuk, Hall, \& Siders, 1986).

\section{Biochemical tests}

Blood samples were collected from the median cubital vein by a trained biochemist after $8 \mathrm{~h}$ fasting. Vacuum collection tubes with EDTA- $\mathrm{K}_{3}$ were used for haematology (A1C and fasting plasma glucose (FPG)), and tubes with clot accelerator $\left(\mathrm{SiO}_{2}\right)$ and gel separator were used for serology (fructosamine). The samples were analysed in the Clinical Laboratory, Division of Health, at the Universidade Federal de Viçosa. The following methods were used for analysis: (a) glycated haemoglobin (A1C): highperformance liquid chromatography (HPLC), using a VARIANT II System (Bio-Rad Laboratories, Inc., USA) with reference value (RV) for normality $\leq 6.5 \%$ (American Diabetes Association, 2014); (b) fructosamine: colorimetric with reduction of nitroblue tetrazolium using a modular (Roche) device, with a normal RV of $205-285 \mu \mathrm{mol} \cdot \mathrm{L}^{-1}$ and (c) FPG: glucose oxidase method in a Cobas Mira Plus (Roche) device, with an RV for diabetes $\geq$ $126 \mathrm{mg} \cdot \mathrm{dL}^{-1}\left(7.0 \mu \mathrm{mol} \cdot \mathrm{L}^{-1}\right)$ (American Diabetes Association, 2014).

\section{Physical activity levels}

PAL were measured using an ActiGraph GT3X (ActiGraph $^{\mathrm{TM}}$, Pensacola, FL, USA) accelerometer with filtering algorithms validated to accurately measure the amount and intensity of human activity, as widely used in studies of this nature (Hagstromer, Oja, \& Sjostrom, 2007; Matthews et al., 2008; Melanson \& Freedson, 1995). The ActiGraph GT3X is a tri-axial accelerometer measuring $3.8 \mathrm{~cm} \times 3.7 \mathrm{~cm} \times 1.8 \mathrm{~cm}$, weighing $27 \mathrm{~g}$ and with a storage capacity of $16 \mathrm{MB}$ or 400 days. Accelerometers used by participants were fixed with an elastic belt around the hip on the right side for 3 consecutive days -2 weekdays and 1 weekend day (Sasaki, John, \& Freedson, 2011), except during water-based activities or during sleep (Colley, Gorber, \& Tremblay, 2010).

Data were recorded at 60 -s intervals and analysed using the software ActiLife 5.10.0 and Firmware 4.2.0 (ActiGraph $^{\mathrm{TM}}$, Pensacola, FL, USA). Wear time validation was defined according Choi and colleagues (Choi, Liu, Matthews, \& Buchowski, 2011). For energy expenditure (daily activity (kcal)), we selected the algorithm that uses the vector magnitude composite as the predictor variable. PAL is 
expressed as total counts per minute (counts $\cdot \mathrm{min}^{-1}$ ) and was classified in categories according to diabetes cut-off points (Lopes, Magalhaes, Bragada, \& Vasques, 2009) (sedentary $\leq 200$; light $=201-$ 1239 ; moderate $=1240-2399$; and vigorous $\geq 2400$ ) and vector magnitude cut-off points (Aguilar-Farias, Brown, \& Peeters, 2013; Sasaki et al., 2011) (sedentary $\leq 200$; light $=201-2690 ;$ moderate $=2691-$ 6166 ; vigorous $=6167-9642$ and very vigorous $\geq 9643$ ). For the intervention period, participants did not wear accelerometer on the same days that they practised exercise in the laboratory.

Data were adjusted based on the average awake time of $19 \mathrm{~h}$ (estimated awake time for this population). The counts $\cdot \min ^{-1}$ and the number of minutes in the different intensity intervals were proportionally adjusted with the following equation: counts $\cdot \min ^{-1}$ adjusted $=$ (counts $\cdot \min ^{-1}$ of the day) $\times(1901 \times 60 \div$ total time of the day in minutes), adapted from Andersen and colleagues (Andersen et al., 2006).

\section{Cardiorespiratory fitness}

Participants' cardiorespiratory fitness was measured using the metabolic gas analyser VO2000 (Medical Graphics Corporation, Saint Paul, MN, USA) and analysed using the software Aerograph 4.3 (Medical Graphics Corporation). The metabolic gas analyser was automatically calibrated before each test. Cardiorespiratory fitness tests were performed on a cycle ergometer (ISO1000, SCIFIT ${ }^{\circledR}$ Corporate Headquarters, Tulsa, OK, USA). All necessary precautions for performing cardiorespiratory fitness tests in diabetic patients (e.g. blood pressure measurement at rest and during testing, measurement of blood glucose before and after the test) were taken.

Prior to cardiorespiratory fitness tests, participants became acclimatised to the cycle ergometer through a 5-min warm-up. Participants underwent an individualised ramp protocol according to the criteria established by da Silva and colleagues (da Silva, Monteiro, Cunha, Myers, \& Farinatti, 2012) with increments by minute, until reaching $85 \%$ of heart rate $(\mathrm{HR})$ estimated by $\mathrm{HR}_{\max }=208-($ age $\times 0.7)$ proposed by Tanaka and colleagues (Tanaka, Monahan, \& Seals, 2001). As no physician was present during the test, for safety reasons, we interrupted the cardiorespiratory fitness test when the participants reached $85 \%$ of maximal $\mathrm{HR}$, and started the recovery stage. Test data $\left(\mathrm{HR}\right.$ and $\left.\mathrm{VO}_{2}\right)$ were used as a basis for the development of individual equations to estimate peak oxygen consumption $\left(\mathrm{VO}_{2}\right.$ peak) by linear regression (Ekelund, Franks, Sharp, Brage, \& Wareham, 2007) SigmaPlot $^{\circledR}$ Version 11.0; Systat Software, Inc., Chicago, IL, USA).

\section{Protocol}

The study lasted 12 weeks, during 8 of which the exercise intervention was performed (3rd to 10th weeks). Exercises were performed in the Human Performance Laboratory, at the Universidade Federal de Viçosa, using cycle ergometers (Cycle 167, 2001, ERGO-FIT ${ }^{\circledR}$ ).

Exercises were performed 3 days per week $\left(\mathrm{d} \cdot \mathrm{wk}^{-1}\right.$ ) over 8 weeks. Throughout the study, each bout of exercise ranged from 30 to $60 \mathrm{~min}$ and intensity gradually increased from $50 \%$ to $60 \%$ of $\mathrm{VO}_{2}$ peak. Drawing of the progression of the study was based on the work of Moura and colleagues (Moura et al., 2014). Each training bout was divided into three phases: warm-up, exercises and cooldown. Warm-up and cool-down always lasted 5 min each.

The intensity of exercise based on $\mathrm{VO}_{2}$ peak was controlled by monitoring the corresponding HR (Polar ${ }^{\circledR}$ RS800CX, Finland). Participants were asked to maintain an average speed of $20 \mathrm{~km} \cdot \mathrm{h}^{-1}$ throughout the exercise and the load (watts) on the cycle ergometer was increased to achieve the target $\mathrm{HR}$ based on the percentage $\mathrm{VO}_{2}$ peak for the specific bout. However, if a participant showed peripheral fatigue, the load (watts) on the cycle ergometer was reduced and the exercise speed was increased, in order to maintain the required physiological load (HR).

We did not control the food intake of the participants and they were asked to maintain their usual diet during the exercise intervention. PAL was measured during the 1st, 8th and 12th weeks. Biochemical tests, cardiorespiratory fitness, anthropometric assessment and body composition were measured in the 2 nd and 11 th weeks.

\section{Statistics}

All variables passed the normality test (ShapiroWilk) and equal variance test. Data were tested with parametric statistics, but did not present statistical differences. Therefore, due to the small sample size, we decided to use non-parametric tests for analysis. The data are presented as means $(\bar{x})$, standard deviation (s), median (Md) and percentage (\%). We used Mann-Whitney test to compare weekdays vs. weekend days for vector magnitude, counts, daily activity (kcal) and steps/day. The Friedman test was used to evaluate the change in PAL, daily activity (kcal) and steps/day between the intervention periods. The Wilcoxon test was used to compare anthropometric and physiological variables pre- and post-intervention. $P$ values $<0.05$ were considered significant. The analyses were performed using the 
software SigmaPlot ${ }^{\circledR}$ version 11.0 (Systat Software, Inc., Chicago, IL, USA).

\section{Results}

We found no statistically significant differences in PAL in type 2 diabetes patients between intervention periods (Figures 1 and 2). We also did not find any statistical differences between vector magnitude, counts, daily activity (kcal) and steps/day. In other words, the participants in this research did not show changes in PAL on weekdays compared with weekend days. On the other hand, we found statistically significant increases in maximal oxygen intake $(P=0.03)$ and blood concentrations of fructosamine $(P=0.03)$ pre- and post-intervention (Table I).

The data demonstrate that diabetic patients spend the majority of their awake time in sedentary activities $\left(\leq 200\right.$ counts $\left.\cdot \min ^{-1}\right)$. We can verify that for sedentary classification, diabetes cut-off points (Lopes et al., 2009) present greater proportion than the vector magnitude cut-off points (Aguilar-Farias et al., 2013; Sasaki et al., 2011) (Figure 2). Only 3\% of awake time (pre-, during and post-intervention) was spent in activities considered as moderate (1240-2399 counts $\cdot \mathrm{min}^{-1}$ ) (Figure 2A); this distribution is very similar to the distribution of magnitude cut-off points (Figure 2B).

We also analysed the energy expenditure estimated by accelerometer for physical activity, as well as the number of daily steps performed by the participants. They showed an energy expenditure of $533.9,638.2$ and $608.0 \mathrm{kcal} \cdot \mathrm{day}^{-1}(P=0.654)$ (pre-, during and post-intervention, respectively) and performed 9181, 10011 and 10353 steps/day $(P=0.654)$ (pre-, during and post-intervention, respectively), but both showed no statistical differences between the periods. Data are presented as median.

Anthropometric variables, body composition, A1C and FPG did not differ significantly between pre- and post-intervention (Table 1). According to the BMI classification of the World Health Organization (WHO, 2003), participants were
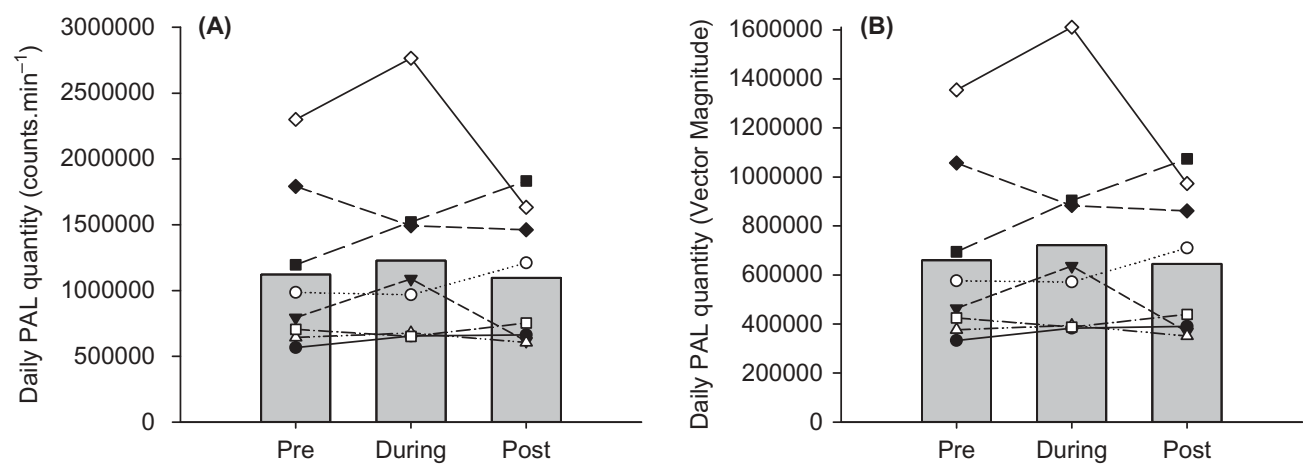

Figure 1 . Median of physical activity levels (counts $\cdot \mathrm{min}^{-1}$ ) per day in each study period.

Daily physical activity assessed by diabetes cut-off points (A) (Lopes et al., 2009) and vector magnitude cut-off points (B) (Aguilar-Farias et al., 2013; Sasaki et al., 2011) in each study period. Vertical bars show the data as median and lines show the individual data. There was no statistically significant difference between periods for each variable analysed. Friedman test $(P>0.05)$.
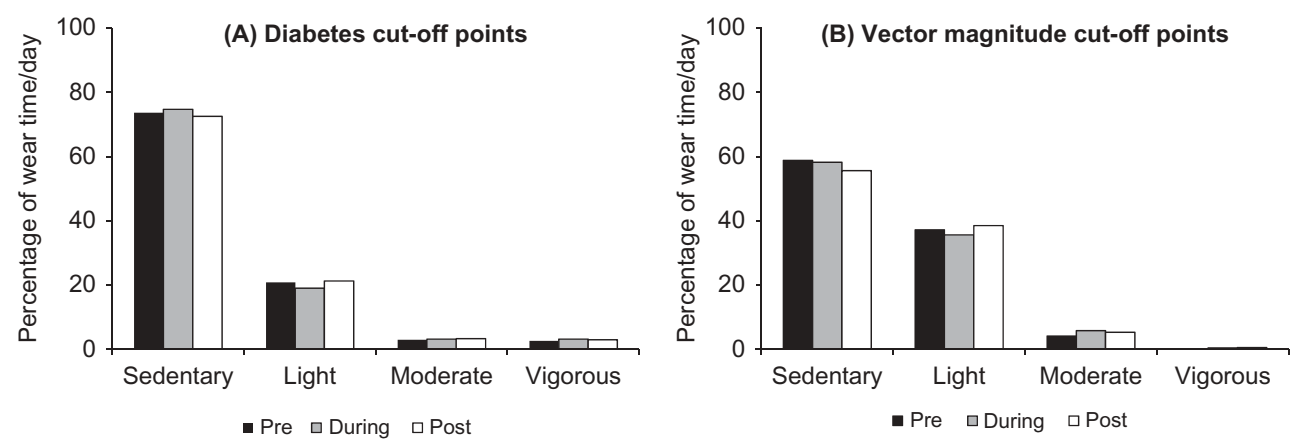

Figure 2. Distribution of awake time percentages per day spent in physical activity of different levels in each study period.

Distribution of the percentage of time wearing accelerometer per day in each category of physical activity evaluated in each period of the study using different cut-off points. A - diabetes cut-off points (Lopes et al., 2009) and B - vector magnitude cut-off points (Aguilar-Farias et al., 2013; Sasaki et al., 2011). Data are shown as median. There was no statistically significant difference between physical activity intensities in each study period. Friedman test $(P>0.05)$. 
Table I. Anthropometric variables, body composition, biochemical tests and $\mathrm{VO}_{2}$ peak of participants pre-intervention $(n=8)$ and postintervention $(n=8)$.

\begin{tabular}{|c|c|c|c|c|}
\hline \multirow[b]{2}{*}{ Variables } & \multicolumn{2}{|c|}{ Pre $(n=8)$} & \multicolumn{2}{|c|}{ Post $(n=8)$} \\
\hline & $\bar{x} \pm \mathbf{s}$ & $\mathrm{Md}$ & $\bar{x} \pm \mathbf{s}$ & $\mathrm{Md}$ \\
\hline Weight (kg) & $83.7 \pm 17.1$ & 79.1 & $83.2 \pm 17.7$ & 78 \\
\hline BMI $\left(\mathbf{k g} \cdot \mathbf{m}^{-2}\right)$ & $30.2 \pm 6.4$ & 28.1 & $29.8 \pm 6.2$ & 28 \\
\hline WC (cm) & $102.6 \pm 12.0$ & 98.2 & $97.5 \pm 20.1$ & 100 \\
\hline$\%$ fat & $33.4 \pm 6.3$ & 33.3 & $32.4 \pm 5.9$ & 31.7 \\
\hline A1 C (\%) & $8.9 \pm 1.6$ & 9.2 & $8.3 \pm 1.8$ & 8.7 \\
\hline Fructosamine $\left(\mu \mathrm{mol} \cdot \mathbf{L}^{-1}\right)$ & $379.6 \pm 92.0$ & 365.5 & $323 \pm 69.4$ & $322.5^{\star}$ \\
\hline FPG $\left(\mathbf{m g} \cdot \mathbf{d L}^{-1}\right)$ & $192.2 \pm 73.9$ & 193.5 & $176.7 \pm 55.1$ & 194.5 \\
\hline VO $O_{2}$ peak $\left(\mathrm{ml} \cdot \mathrm{kg}^{-1} \cdot \min ^{-1}\right)$ & $25.7 \pm 5.1$ & 25.1 & $29.5 \pm 6.6$ & $27.3^{\star}$ \\
\hline
\end{tabular}

Notes: ${ }^{\star}$ Statistically significant difference pre- and post-intervention (Wilcoxon test, $P=0.039$ ).

Legend: $\mathrm{BMI}=$ Body mass index; $\mathrm{WC}=$ Waist circumference; $\%$ fat $=$ Fat percentage; $\mathrm{A} 1 \mathrm{C}=$ Glycated haemoglobin; FPG $=$ Fasting plasma glucose $; \mathrm{VO}_{2}$ peak $=$ Peak oxygen consumption. Data are presented as mean $(\bar{x})$, standard deviation $(\mathrm{s})$ and median $(\mathrm{Md})$.

classified as having obesity level I, which was confirmed by the high percentage of body fat measured using the bioimpedance technique.

\section{Discussion}

Our study is the first to investigate the compensatory effects of aerobic exercise on PAL in type 2 diabetes patients. We found that the exercise programme used had no compensatory effects on PAL in the participants evaluated (Figures 1 and 2), although they did show an improvement in physical fitness.

In a study conducted by Meijer and colleagues (Meijer, Westerterp, \& Verstappen, 1999), who assessed the effects of 12 weeks of exercise on PAL in older adults using tri-axial accelerometers, it was found that when subjected to moderate-intensity exercise, they improved their physical fitness and decreased their PAL. The improvement in physical fitness is consistent with our results, although we found no changes in PAL. This difference between the results may have been influenced by the high proportion of PAL classified as sedentary at baseline in our study.

In a recent research, Kozey-Keadle and colleagues (Kozey-Keadle et al., 2013) investigated whether individuals undergoing a physical training would compensate with modifying non-exercise behaviour. The authors concluded that there were no statistically significant changes; however, there is a tendency of behaviour modification, since approximately $50 \%$ of the participants increased sedentary time and decreased non-exercise physical activity. All health professionals should advise their clients and patients to be increasingly physically active, especially by increasing non-exercise physical activity (e.g. daily activities, leisure time, occupational, housework and transport-related activity).

Our results demonstrate that diabetic patients spend the majority of their awake time in sedentary and light activities (Figure 2). Thus, these results highlight the need for a change in lifestyle, supplementing sedentary activities by increasing PAL. Studies conducted in diabetics (Manders, Van Dijk, \& Van Loon, 2010) and non-diabetics (Buman et al., 2010) have demonstrated the beneficial effects of light physical activity on improving glycaemic control and quality of life.

Some epidemiological studies have verified the relationship between PAL and the incidence of diseases such as obesity (Metallinos-Katsaras, Freedson, Fulton, \& Sherry, 2007) and diabetes (Meisinger et al., 2005), in addition to cardiovascular complications (Woolf et al., 2008). Matthews and colleagues (Matthews et al., 2008) and Metzger and colleagues (Metzger et al., 2008) investigated the amount of time spent performing sedentary behaviour and physical activity patterns in adults and concluded that Americans spend the majority of their awake time in light PAL.

In contrast, a study in a Chinese population (Ma et al., 2008) examined the association between PAL and metabolic syndrome using dietary and physical activity recall. The percentage of people considered sedentary, low active, active and very active was 12.3, 13.7, 20.1 and 53.9, respectively. However, although such data are derived from subjective measures of PAL, they differ from findings in Western populations such as in our study. These differences can be attributed to the influence of the different lifestyles adopted in each population.

On the other hand, our results showed a trend for (not statistically significant) positive behavioural modification in both the number of steps/day (533.9 to 608.0 - an increase of $13.9 \%$ ) and daily energy expenditure (9181 to 10353 - increase of $12.7 \%$ ) of participants. This behaviour is in agreement with the recommendation proposed by TudorLocke and Schuna (Tudor-Locke \& Schuna, 2012) for the prevention of type 2 diabetes - adults avoid approximately $<5000$ steps/day and strive to 
approximately $\geq 7500$ steps/day. Thus, all health professionals should pay more attention to PA behaviour that takes place outside the exercise programme and recommend their patients to be more physically active through different occasions of their daily routine.

Our study has several limitations. The small sample size limits the extrapolation of the results. This problem arose due to inherent difficulties in finding volunteers with type 2 diabetes without microvascular diseases or other complications, who were able to participate in a controlled exercise programme for 8 weeks. Another limitation was the lack of control over food intake, despite recommendations to maintain their usual diets that were continually reinforced throughout the intervention period.

Nevertheless, besides the fact that our study is the first to investigate the compensatory effects of aerobic exercise on PAL in type 2 diabetes patients, it has another strength - that is, the objective measurement of PAL using tri-axial accelerometers (Melanson \& Freedson, 1995).

Exercise and physical activity, in addition to drug therapy and dietary re-education, are essential components for the treatment and care of diabetes. Thus, we believe that all health professionals should employ the correct use of the terms "exercise" and "physical activity", educating patients about the real difference between them. We should always encourage patients to be more physically active and to highlight the importance of physical activity and exercise. Although in clinical practice we have identified that many patients report being sedentary (for not practising exercises), in further research we found that in fact these patients are not sedentary in relation to daily physical activity.

\section{Conclusions}

We conclude that the exercise programme used in our study had no compensatory effects on PAL in type 2 diabetes patients, although they showed improvements in their physical fitness $\left(\mathrm{VO}_{2}\right.$ peak) and reduced blood concentrations of fructosamine.

However, further studies with a larger sample, diet control and exercise programmes with constant workload increments should be performed to determine whether aerobic exercise or other exercise programmes with different intensities are able to induce compensatory effects on PAL in type 2 diabetics.

\section{Acknowledgements}

We thank FAPEMIG for the scholarship to BPM (Department of Physical Education, Human Performance Laboratory, Universidade Federal de
Viçosa, Viçosa, Minas Gerais, Brazil), CNPq for scholarship to BPPS (Department of Physical Education, Human Performance Laboratory, Universidade Federal de Viçosa, Viçosa, Minas Gerais, Brazil) and the FUNARPÓs for financing the procedures performed in this study. In addition, we thank the volunteers who kindly participated in the study and BPPS who was responsible for overseeing the exercise training of volunteers.

\section{Competing interests}

The authors declare that they have no competing interests.

\section{Funding}

This work was supported by FAPEMIG (Foundation for Research Support of Minas Gerais State), CNPq (The National Council for Scientific and Technological Development) and FUNARPÓS (FUNARBE Program of Support the Graduate of Universidade Federal de Viçosa).

\section{References}

Aguilar-Farias, N., Brown, W. J., \& Peeters, G. M. (2013). ActiGraph GT3X+ cut-points for identifying sedentary behaviour in older adults in free-living environments. Fournal of Science and Medicine in Sport, 13, 1-7.

American Diabetes Association. (2014). Standards of medical care in diabetes-2014. Diabetes Care, 37(Suppl 1), S14-S80.

Andersen, L. B., Harro, M., Sardinha, L. B., Froberg, K., Ekelund, U., Brage, S., \& Anderssen, S. A. (2006). Physical activity and clustered cardiovascular risk in children: A crosssectional study (The European Youth Heart Study). The Lancet, 368(9532), 299-304.

Boulé, N. G., Kenny, G. P., Larose, J., Khandwala, F., Kuzik, N., \& Sigal, R. J. (2013). Does metformin modify the effect on glycaemic control of aerobic exercise, resistance exercise or both? Diabetologia, 56(11), 2378-2382.

Buman, M. P., Hekler, E. B., Haskell, W. L., Pruitt, L., Conway, T. L., Cain, K. L., \& King, A. C. (2010). Objective lightintensity physical activity associations with rated health in older adults. American fournal of Epidemiology, 172(10), 11551165.

Caspersen, C. J., Powell, K. E., \& Christenson, G. M. (1985). Physical activity, exercise, and physical fitness: Definitions and distinctions for health-related research. Public Health Reports, 100(2), 126-131.

Choi, L., Liu, Z., Matthews, C. E., \& Buchowski, M. S. (2011). Validation of accelerometer wear and nonwear time classification algorithm. Medicine \& Science in Sports \& Exercise, 43(2), 357-364.

Colberg, S. R., Sigal, R. J., Fernhall, B., Regensteiner, J. G., Blissmer, B. J., Rubin, R. R., ... Braun, B. (2010). Exercise and type 2 diabetes: The American college of sports medicine and the American Diabetes Association: Joint position statement. Diabetes Care, 33(12), e147-167.

Colley, R., Gorber, S. C., \& Tremblay, M. S. (2010). Quality control and data reduction procedures for accelerometryderived measures of physical activity. Health Reports, 21(1), 63-69. 
da Silva, S. C., Monteiro, W. D., Cunha, F. A., Myers, J., \& Farinatti, P. T. (2012). Determination of best criteria to determine final and initial speeds within ramp exercise testing protocols. Pulmonary Medicine, 2012, 1-10.

Ekelund, U., Franks, P. W., Sharp, S., Brage, S., \& Wareham, N. J. (2007). Increase in physical activity energy expenditure is associated with reduced metabolic risk independent of change in fatness and fitness. Diabetes Care, 30(8), 2101-2106.

Hagstromer, M., Oja, P., \& Sjostrom, M. (2007). Physical activity and inactivity in an adult population assessed by accelerometry. Medicine E Science in Sports \& Exercise, 39(9), 1502-1508.

King, N. A., Caudwell, P., Hopkins, M., Byrne, N. M., Colley, R., Hills, A. P., ... Blundell, J. E. (2007). Metabolic and behavioral compensatory responses to exercise interventions: Barriers to weight loss. Obesity (Silver Spring), 15(6), 1373-1383.

King, N. A., Hopkins, M., Caudwell, P., Stubbs, R. J., \& Blundell, J. E. (2008). Individual variability following 12 weeks of supervised exercise: Identification and characterization of compensation for exercise-induced weight loss. International fournal of Obesity, 32(1), 177-184.

Kozey-Keadle, S., Staudenmayer, J., Libertine, A., Mavilia, M., Lyden, K., Braun, B., \& Freedson, P. (2013, October 31). Changes in sedentary time and physical activity in response to an exercise training and/or lifestyle intervention. Fournal of Physical Activity \& Health. Advance online publication. PMID: 24184493. Retrieved from http://goo.gl/Aw4iLi

Levine, J. A. (2004). Non-exercise activity thermogenesis (NEAT). Nutrition Reviews, 62(7), S82-S97.

Lindstrom, J., Neumann, A., Sheppard, K. E., Gilis-Januszewska, A., Greaves, C. J., Handke, U., ... Yilmaz, T. (2010). Take action to prevent diabetes-the IMAGE toolkit for the prevention of type 2 diabetes in Europe. Hormone and Metabolic Research, 42(Suppl 1), S37-S55.

Lohman, T. G., Roche, A. F., \& Martorell, R. (1988). Anthropometric standardization reference manual. Champaign, IL: Human Kinects.

Lopes, V. P., Magalhaes, P., Bragada, J., \& Vasques, C. (2009). Actigraph calibration in obese/overweight and type 2 diabetes mellitus middle-aged to old adult patients. Fournal of Physical Activity \& Health, 6(Suppl 1), S133-S140.

Lukaski, H. C., Bolonchuk, W. W., Hall, C. B., \& Siders, W. A. (1986). Validation of tetrapolar bioelectrical impedance method to assess human body composition. Fournal of Applied Physiology, 60(4), 1327-1332.

Ma, G., Luan, D., Li, Y., Liu, A., Hu, X., Cui, Z., ... Yang, X. (2008). Physical activity level and its association with metabolic syndrome among an employed population in China. Obesity Reviews, 9(Suppl 1), 113-118.

Manders, R. J., Van Dijk, J. W., \& Van Loon, L. J. (2010). Lowintensity exercise reduces the prevalence of hyperglycemia in type 2 diabetes. Medicine $\mathcal{E}$ Science in Sports $\mathcal{E}$ Exercise, 42(2), 219-225.

Matthews, C. E., Chen, K. Y., Freedson, P. S., Buchowski, M. S., Beech, B. M., Pate, R. R., \& Troiano, R. P. (2008). Amount of time spent in sedentary behaviors in the United States, 20032004. American fournal of Epidemiology, 167(7), 875-881.

Meijer, E. P., Westerterp, K. R., \& Verstappen, F. T. (1999). Effect of exercise training on total daily physical activity in elderly humans. European fournal of Applied Physiology and Occupational Physiology, 80(1), 16-21.

Meisinger, C., Lowel, H., Thorand, B., \& Doring, A. (2005). Leisure time physical activity and the risk of type 2 diabetes in men and women from the general population. The MONICA/KORA Augsburg cohort study. Diabetologia, 48(1), 27-34.

Melanson Jr., E. L., \& Freedson, P. S. (1995). Validity of the computer science and applications, Inc. (CCA) activity monitor. Medicine E Science in Sports \& Exercise, 27(6), 934-940.

Metallinos-Katsaras, E. S., Freedson, P. S., Fulton, J. E., \& Sherry, B. (2007). The association between an objective measure of physical activity and weight status in preschoolers. Obesity (Silver Spring), 15(3), 686-694.

Metzger, J. S., Catellier, D. J., Evenson, K. R., Treuth, M. S., Rosamond, W. D., \& Siega-Riz, A. M. (2008). Patterns of objectively measured physical activity in the United States. Medicine E Science in Sports E Exercise, 40(4), 630-638.

Moura, B. P., Amorim, P. R., Silva, B. P., Franceschini, S. C., Reis, J. S., \& Marins, J. C. (2014). Effect of a short-term exercise program on glycemic control measured by fructosamine test in type 2 diabetes patients. Diabetology $\mathbb{E}$ Metabolic Syndrome, 6(1), 16.

Moura, B. P., Natali, A. J., Marins, J. C., \& Amorim, P. R. (2011). Different approaches of physical training used in the management of type 2 diabetes: A brief systematic review of randomised clinical trials. The British Fournal of Diabetes $\mathbb{E}$ Vascular Disease, 11(4), 210-216.

Paulweber, B., Valensi, P., Lindström, J., Lalic, N. M., Greaves, C. J., McKee, M., \& Yilmaz, T. (2010). A European evidencebased guideline for the prevention of type 2 diabetes. Hormone and Metabolic Research, 42(Suppl 1), S3-S36.

Sasaki, J. E., John, D., \& Freedson, P. S. (2011). Validation and comparison of ActiGraph activity monitors. Fournal of Science and Medicine in Sport, 14(5), 411-416.

Tanaka, H., Monahan, K. D., \& Seals, D. R. (2001). Age-predicted maximal heart rate revisited. Fournal of the American College of Cardiology, 37(1), 153-156.

Tudor-Locke, C., \& Schuna Jr., J. M. (2012). Steps to preventing type 2 diabetes: Exercise, walk more, or sit less? Frontiers in Endocrinology, 3, 1-7.

WHO. (2003). World Health Organization. Diet, nutrition and the prevention of chronic diseases. World Health Organization Technical Report Series, 916, 1-149.

Woolf, K., Reese, C. E., Mason, M. P., Beaird, L. C., Tudor-Locke, C., \& Vaughan, L. A. (2008). Physical activity is associated with risk factors for chronic disease across adult women's life cycle. Fournal of the American Dietetic Association, 108(6), 948-959.

Yates, T., Davies, M. J., Edwardson, C., Bodicoat, D. H., Biddle, S. J., \& Khunti, K. (2014). Adverse responses and physical activity: Secondary analysis of the PREPARE Trial. Medicine $\mathcal{E}$ Science in Sports $\&$ Exercise, Advance online publication. doi:10.1249/MSS.0000000000000260

Yates, T., Davies, M. J., Henson, J., Troughton, J., Edwardson, C., Gray, L. J., \& Khunti, K. (2012). Walking away from type 2 diabetes: Trial protocol of a cluster randomised controlled trial evaluating a structured education programme in those at high risk of developing type 2 diabetes. BMC Family Practice, $13,46$. 